that the ribonucleic acid of the virus is large enough to carry much more information than that which is required for controlling the primary structure of the protein unit contained in the finished virus. This raises several problems for future research. $H$. Fraenkel-Conrat also reported very interesting results on a special state of the virus ribonucleic acid at the beginning of infection.

Another approach to the specific function of ribonucleic acid in protein synthesis is the artificial modification of the structure of the acid. This has been done by chemical means in the case of virus ribonucleic acid. In bacteria, composition of the acid can be changed by growing the organisms in the presence of analogues of the normal purines or pyrimidines. F. Gros (Institut Pasteur, Paris) gave a very clear account of research on the effects of fluorouracil on protein synthesis in $E$. coli. Incorporation of all the individual amino-acids does not respond in the same way to fluorouracil. For example, the incorporation of proline and tyrosine is depressed whereas that of arginine is stimulated. These changes appear to reflect qualitative as well as quantitative modifications in the protein equipment of the organism, indicating that the analogue may actually interfere with the agents which control protein structure. A phosphatase formed in the presence of the analogue has a normal enzymic activity although it contains less proline than the normal enzyme; thus it is probably slightly modified at a place which is not important for the catalytic properties of the protein. On the contrary, $\beta$.galactosidase synthesis is abolished and replaced by the formation of some related inactive protein. It is striking that fluorouracil specifically reduces the fixation of proline and of tyrosine on soluble ribonucleic acid at the same time as it reduces the incorporation of these same amino-acids into the proteins. This indicates that soluble ribonucleic acid plays an important part in the specificity of protein formation. These results also support current views according to which activated amino-acids are bound to soluble ribonucleic acid before condensing into polypeptides.

T. Hultin (Wenner Gren Institute, Stockholm) reported observations on animal tissues which indicate that another pathway of amino-acid incorporation might exist beside that passing through soluble ribonucleic acid. That the latter must also be operative was shown by several of his results which agree with the classical scheme. However, he obtained, by means of new techniques of isolation of ribosomes and by fractionation of supernatant preparations, a system in which amino-acids are incorporated into proteins in the particles in the absence of soluble ribonucleic acid. A protein of the supernatant is required for incorporation with this system. Protein synthesis which can occur in isolated mitochondria or nuclei appears to depend on the presence in these cell organelles of particles closely resembling the ribosomes of the cytoplasmic ground substance.

Of great benefit to the meeting was the presence in the audience of biochemists from different countries who had taken part a few days before in Brussels in the Solvay Conference on Nucleoproteins. All the lectures were followed by very good discussions. The meeting was closed by a general discussion which concerned the function of the various ribonucleic acid fractions, the transfer of information from gene to protein, and coding problems.

H. Chantrenne

\title{
PROGRESS IN GAS CHROMATOGRAPHY
}

\begin{abstract}
$\mathrm{A}^{\mathrm{N}}$ N informal symposium of the Gas Chromatography Discussion Group (associated with the Hydrocarbon Research Group of the Institute of Petroleum) was held at the University of Bristol on September 25 under the chairmanship of Mr. C. S. G. Phillips.

Dr. F. H. Pollard commented on the enthusiasm and free interchange of ideas among workers in this field which was undoubtedly responsible for the present advanced state of the art. Having regard to the success achieved by him in the field of inorganic separations by paper chromatography, it was not surprising that he should mention the possible separation of such materials by gas chromatography.

The outstanding feature of the meeting was the demonstration by Mr. R. P. W. Scott of the presentation of gas chromatographie data with a high-persistence cathode ray tube. With capillary columns it is possible to effect separations at speods much greater than the response of conventional recorders, and in order to take full advantage of the technique in its application to kinetic and other studies a means of high-speed recording is essential. Mr. Scott, using a $70-\mathrm{ft}$. column, demonstrated separations of $100^{\circ} \mathrm{C}$. boiling-range samples in less than $1 \mathrm{~min}$. with his apparatus which, inclusive of automatic repetitive sample injection system, cost less than $\mathfrak{£ 8 0}$ for materials.

The discussion which followed a paper by $\mathbf{M r}$.
\end{abstract} C. I. A. Harbourn on quantitative determinations showed that this aspect of the subject is one that affects most users of the technique. As yet, however, if one uses the published literature as a guide, it would appear to have received very little attention. The well-prepared paper covered methods of peak measurement, sources of error and repeatability of calibration, internal standard, and normalization mothods, and interpretation of unresolved peaks. Recent developments in integrators and the use of analogue computers and tape recorders were also discussed.

Some of the practical aspects of the measurement of retention volumes were dealt with by Dr. G. W. A. Rijnders, and Dr. C. R. Patrick mentioned some of the problems attached to 'scaling-up' analytical columns to sizes capable of handling up to $10 \mathrm{gm}$. samples. The values of height equivalent of a theoretical plate (H.E.T.P.) increase and the much higher volumetric flow-rates necessitate modifications to the design of hot-wire detectors. Mr. D. H. Desty read a paper by Dr. J. Janak, who unfortunately was unable to be present, describing the application of gas chromatography to the identification of structure of involatile substances by pyrolysis and subsequent analysis of the products.

Members attending, among whom were some from the United States and Europe, were able to inspect and see working a good selection of the commercial instruments now available for laboratory and process control work.
C. G. ScotT 